\title{
A ASSOCIAÇÃO BRASILEIRA DE PESQUISADORES/AS NEGROS (ABPN) E OS NÚCLEOS DE ESTUDOS AFRO-BRASILEIROS (NEABS): PRODUÇÕES ANTIRRACISTAS
}

\author{
THE BRAZILIAN ASSOCIATION OF BLACK RESEARCHERS (ABPN) AND \\ THE AFRO-BRAZILIAN STUDY CENTERS (NEABS): ANTIRACIST PRODUCTIONS
}

\begin{abstract}
Resumo
Neste artigo, trazemos uma abordagem preliminar da pesquisa "A Associação Brasileira de Pesquisadores/as Negros (ABPN) e os Núcleos de Estudos afro-brasileiros (Neab's): produções antirracistas". Tecemos algumas reflexões a partir do surgimento destas associações, buscando compreender o alcance das suas produções na contribuição para a efetivação de uma educação plural e antirracista. Esta pesquisa adotará, do ponto de vista do método, a proposta teórica a partir dos estudos de Bakthin, em especial o conceito de dialogia. Utilizaremos, enquanto procedimento metodológico, a análise textual discursiva, que tem se mostrado ferramenta importante, permitindo conviver com uma abordagem que exige constantemente a (re)construção de caminhos dentro da pesquisa. Acreditamos que este procedimento metodológico, adotado aqui, criará espaços para a emergência do novo, precedendo a criação de novas ordens e entendimentos. Destacamos, também, a importância desta pesquisa para o fortalecimento daqueles/as espaços que agrupam e estudam o campo das relações raciais e educação.
\end{abstract}

Palavras-chave: Produção intelectual negra; Formação de professores/as; Conhecimentos conta-hegemônicos; Dialogia.

\begin{abstract}
:
In this article, we present a preliminary approach to the research: "The Brazilian Association of Black Researchers and the Kernel of Afro-Brazilian Studies: possible contributions to the implementation of an antiracist and pluricultural education." We draw some reflections from the emergence of these associations, seeking to understand the scope of their productions in the contribution to the realization of a plural and antiracist education. This research will adopt, from the point of view of the method, the theoretical proposal from Bakthin's studies, especially the concept of dialogia. We will use, as methodological procedure, the discursive textual analysis, which has been shown to be an open tool, allowing us to live with an approach that constantly demands the (re) construction of paths within the research. We believe that this methodological
\end{abstract}


procedure, adopted here, will create spaces for the emergence of the new, preceding the creation of new orders and understandings.

Keywords: Black intellectual production; Teacher training; Account-hegemonic knowledge; Dialogia.

\section{INTRODUÇÃO}

Este texto traz abordagem preliminar de uma pesquisa ${ }^{1}$, na qual tecemos algumas reflexões a partir do surgimento da Associação Brasileira de Pesquisadores/as Negros/as - ABPN e dos Núcleos de Estudos Afro-Brasileiros - Neab's, tema suscitado nos encontros do grupo Firmina - pós - colonialidade: Educação, História, Cultura e Ações Afirmativas² - vinculado à Universidade do Estado da Bahia.

Consideramos as possíveis contribuições das produções escritas destas duas instituições para o campo temático da educação das relações étnico-raciais na formação inicial e continuada de professores/as, a partir do que determina a Lei 10.639/2003, que altera a atual Lei de Diretrizes e Bases da Educação Nacional - LDB tornando obrigatória a inclusão nos currículos oficiais das redes de ensino - pública e privada - a temática: História e Cultura Afro-Brasileira e Africana.

Faremos um levantamento dessas produções, cuja abrangência temporal segue desde a fundação da $\mathrm{ABPN}$, em 2000, quando foi realizado o I Congresso de Pesquisadores/as Negros/as - COPENE, na cidade de Recife, até o último, realizado no ano de 2016, na cidade de Dourados, Mato Grosso do Sul, o que corresponde à realização de nove encontros. Analisaremos, de forma aprofundada, os artigos produzidos pelas instituições, tomando como espaço empírico as pesquisas apresentadas nos anais dos congressos ${ }^{3}$ e nas edições da revista

Pesquisa em curso, cujo título é "A Associação Brasileira de Pesquisadores/as Negros (ABPN) e os Núcleos de Estudos afro-brasileiros (NEABS): possíveis contribuições para a efetivação de uma educação antirracista e pluricultural".

O grupo nasceu a partir de ações de pesquisa, estudos e atividades de formação de professores/as desenvolvidas inicialmente, por um grupo de estudos vinculado ao Programa de Pós-Graduação em Educação e Contemporaneidade da Universidade do Estado da Bahia - UNEB. Essas ações relacionamse aos conteúdos determinados pela Lei Federal 10.639/2003, qual seja, a obrigatoriedade de inclusão de História da África e Cultura Afro-Brasileira nas escolas da Educação Básica. Consolidadas as atividades iniciais, o Grupo passou a desenvolver atividades em parceria com a Universidade Estadual de Feira de Santana - UEFS onde está lotada a vice coordenadora. Tem se empenhado em pesquisas e reflexões que garantem o aprofundamento sobre o conhecimento das experiências históricas das populações negras brasileiras, bem como da saúde da população negra em destaque a Anemia Falciforme e do Empoderamento a partir da estética, nos diversos espaços institucionais de pesquisa e nos Movimentos Sociais Negros.

3 Ressaltando, aqui, a minha participação em uma das comissões organizadoras do IV Congresso Brasileiro de Pesquisadores/as Negros/as - COPENE, realizado de 13 a 16 de setembro de 2006, nas dependências da Universidade do Estado da Bahia em Salvador, com o tema "O Brasil Negro e suas Africanidades: produção e transmissão de conhecimentos”. Lembramos que os encontros nacionais são bianuais. 
eletrônica da Associação ${ }^{4}$, considerando o lançamento do primeiro volume, em 2010, até o seu número mais recente, em 2019.

A ABPN se constitui no I Congresso Brasileiro de Pesquisadores/as Negros/as - I COPENE, realizado no ano de 2000 nas dependências da Universidade Federal de Pernambuco - UFPE - como resultado direto do esforço de alguns pesquisadores/as negros/as, oriundos de diversos espaços institucionais de pesquisa e, também, dos Movimentos Negros que há muito denunciavam sua invisibilidade no interior do campo acadêmico. A ABPN adota a perspectiva da superação do racismo, trabalhando com temas de interesse direto das populações negras no Brasil, na África e na Diáspora, defendendo e zelando pela manutenção de pesquisas com financiamento, propondo medidas para o fortalecimento institucional da temática das relações raciais ${ }^{5}$.

Adotando propostas semelhantes às da ABPN, a articulação dos Neab's é um pouco mais antiga, remontando às iniciativas de professores/as negros/as, oriundos dos cursos de pós-graduação nas décadas de 1980 e 1990, que passaram a integrar o corpo docente em universidades por todo país e, por conseguinte, a formar grupos, núcleos, laboratórios ${ }^{6}$ ou centros de estudos e pesquisas sobre as relações raciais no Brasil.

Segundo Siss, Barreto e Oliveira (2013), os Neab's ganharam forma e força pós-Marcha 1991, no contexto das reivindicações do Movimento Negro brasileiro por ações afirmativas, dada a conjuntura onde ativistas negros/as, em diferentes espaços institucionais, entre os quais se destacam as universidades públicas e órgãos do governo federal, empreenderam movimentos distintos, porém complementares, no combate ao racismo e à discriminação racial. Um desses movimentos ocorre ao longo do processo de preparação e da participação brasileira (representantes do governo brasileiro e do movimento negro nacional) na III Conferência Mundial contra o Racismo, Discriminação Racial, Xenofobia e Intolerância em 2001, na cidade de Durban, na África do Sul, conforme relatam os autores Siss, Barreto e Oliveira (2013).

\footnotetext{
Todas as edições da revista da ABPN são disponibilizadas através do site: http://abpnrevista.org.br/ revista/index.php/revistaabpni/about/submissions .

Disponível em: https://www.abpn.org.br/.

Durante a minha graduação, fiz parte do Laboratório de Cultura Negra. Aprovado pelas instâncias deliberativas do Departamento de Ciências Humanas - Campus V - da Universidade do Estado da Bahia, o órgão possuía estrutura e característica dos chamados NEAB's e foi implantado em 1999, com o objetivo mais amplo de desenvolver atividades de pesquisa, ensino e extensão relacionadas às experiências históricas, culturais, sociais, políticas e pedagógicas das populações negras na Bahia e no Brasil. O referido Laboratório era composto por professores/as - doutores/as e mestres/as - estudantes de graduação e de pós-graduação, funcionários/as e representantes da comunidade externa da região onde se localiza o Departamento.
} 
A ABPN impulsionou o surgimento da rede nacional de Neab's, denominado Consórcio Nacional de Neab's - CONNEAB e ambos se tornaram lócus privilegiados de aglutinação, articulação, debates, propostas de estudos e pesquisas de intelectuais negros/as que atuam com a temática das relações raciais no ambiente acadêmico e não acadêmico ${ }^{7}$. Santos (2008) afirma que, a partir desse fato, estabeleceram-se, enquanto espaços de concentração e circulação de pesquisadores/as de origem ou ascendência negra, portando uma ética de convicção da luta antirracista adquirida ou incorporada do movimento negro e um ethos acadêmico-científico ativo, assim se posicionando em prol das políticas de promoção da igualdade no ambiente universitário e, logicamente, fora dele.

Além de incentivarem o fortalecimento e criação de núcleos e programas de pesquisa especializados nos estudos de temas relacionados aos aspectos socioeducacionais e culturais das populações negras, os Neab's desempenham papel ativo e fundamental na implementação, implantação ${ }^{8}$ e institucionalização da Lei 10.639/2003, das Diretrizes Curriculares Nacionais para a Educação das Relações Étnico-Raciais e para o Ensino de História da Cultura Afro-Brasileira e Africana', bem como o Plano Nacional de Implementação dessas Diretrizes.

Embora tenham surgido no mesmo processo, sendo os seus membros, praticamente, as mesmas pessoas, tanto a ABPN quanto o Consórcio Neab's mantém, além de pontos de encontro que possibilitam atuações conjuntas, algumas especificidades. Enquanto a ABPN abarca um conjunto amplo de pesquisadores/as, o Consórcio Nacional de Neab's tem como foco os interesses de professores/as universitários/as com suas demandas específicas (CARDOSO, 2010). Sendo assim, Marques e Mattos (2016) sugerem que, dada a situação, se tem por finalidade o fortalecimento institucional de seus constituintes, promovendo o acompanhamento e a avaliação das políticas públicas afirmativas nas

\footnotetext{
A Associação Brasileira de Pesquisadores Negros - ABPN, em parceria com o Consórcio Nacional de Núcleos de Estudos Afro-Brasileiros - NEAB's, fundou mais de 150 NEAB's, espalhados por todas as unidades da federação, tornando-se uma das mais importantes organizações antirracistas do país. Assim, dialoga com grandes e tradicionais Organizações Não Governamentais - ONG's, entidades nacionais do Movimento Negro (como Movimento Negro Unificado), UNEGRO, APNS, Coordenação Nacional de Entidades Negras - CONEN, Rede Afro LGBT, Federação Nacional Associações de Pessoas com Doença Falciforme - FENAFAL. Recentemente, em um esforço de internacionalização, integram a Rede Integra - Racismo, Xenofobia e Identidades, UNAM, GT, Universidades Interculturais da CLACSO, REDE IESAL - Ações Afirmativas para Afrodescendentes e Indígenas nas Instituições de Ensino Superior da América Latina e Caribe e WERA - Associação Mundial de Pesquisa em Educação (CARDOSO, 2017).

8 Para Nilma Lino Gomes, o início de toda e qualquer política pública atravessa por um momento inaugural, uma etapa de representação de uma perspectiva que se abre a sociedade, denominada implantação. Depois dessa etapa inaugural é a capacidade política de execução de um plano, projeto que leve à sua prática por meio de providências concretas, denominada implementação (GOMES, 2012, p. 26).

9 Vide Resolução CNE/CP O1/2004 e Parecer do CNE/CP 03/2004.
} 
instituições, proporcionando, também, uma integração de experiências e saberes que constroem o cotidiano de cada Núcleo. (MARQUES; MATTOS, 2016).

De acordo com Macêdo (2013), essas associações reúnem um conjunto heterogêneo de pesquisadores/as, das mais diversas áreas do conhecimento, onde a diversidade é dimensão essencial para a realização de pesquisas multidisciplinares, apresentadas nos seus congressos nacionais. Configuram-se como novidade, concordando com Macêdo (2013), congregando intelectuais que têm como eixo comum abordagens, práticas e relações voltadas para a pesquisa engajada e de enfrentamento ao racismo, potencializadas no contexto das Ações Afirmativas, especialmente da Lei 10.639/2003.

Dessa forma, esses espaços e fóruns são locais que tecem redes de solidariedade, compromissos e construções de conhecimentos ligados às temáticas sobre as populações negras no Brasil, África e Diáspora, firmando-se enquanto campos coletivos de referências epistemológicas e políticas na luta antirracista.

Entendendo que tanto a ABPN quanto os Neab's têm em comum, além de outras funções, o preparo de professores/as para atender a demanda diversificada de estudos das relações étnico-raciais, no que se refere ao trabalho educativo antirracismo no Brasil, destacamos a importância desta pesquisa para o fortalecimento daqueles/as que trabalham e estudam o campo das relações raciais e educação, pois, partilhamos da mesma preocupação de Iolanda (2010) com relação a pouca repercussão dessa produção acadêmica na sociedade civil e, particularmente, na educação básica.

Percebe-se, por exemplo, o significativo crescimento das produções acadêmicas sobre o negro, o aumento de espaços para tais discussões como: Neab's, ABPN, GT 21 da Anped, a criação de cursos e de linhas de pesquisa sobre a questão negra nos cursos de pós-graduação stricto sensu, mas o acesso e a disseminação dos conhecimentos produzidos por estes ainda são muito restritos, o que compromete a apropriação de tais conhecimentos de parte da população. (OLIVEIRA, 2010, p. 217)

Sabendo que ambas as associações são importantes agentes para a consolidação das políticas destinadas às populações negras, verificaremos em que medida suas produções são relevantes para a formação de professores/as, a partir do que determina a Lei 10.639/2003. Afirmamos a importância em elencarmos as produções científicas que desses lugares emergem e suas possibilidades de contribuição para a consolidação de projetos antirracistas nos processos educacionais.

Ao objetivar analisar a produção escrita da ABPN e dos Neab's, torna-se necessário a observância de fatos que envolvam o campo temático da educação das relações étnico-raciais na formação inicial e continuada de 
professores/as contribuindo, assim, para a construção de lugares alternativos, contra-hegemônicos, de (re)configuração das memórias sobre as experiências das populações negras nos processos educacionais, claro, levando em consideração o atual contexto brasileiro das Ações Afirmativas, especialmente a Lei 10.639/2003.

Observaremos o impacto desses conhecimentos na produção intelectual negra brasileira e, também, se esses mesmos saberes têm encontrado terreno fértil para debates no campo educacional da formação de professores/as para a promoção de uma educação antirracista e pluricultural. Refletiremos sobre a diversidade, o crescimento numérico e a qualidade desta produção e se têm influenciado na expansão de novos modelos de análise sobre as experiências coletivas das populações negras e, até que ponto, se tem contribuído para construção de um campo de conhecimento diferenciado, contra-hegemônico, na área da educação.

\section{CONHECIMENTOS CONTRA-HEGEMÔNICOS: PRODUÇÃO INTELECTUAL NEGRA E FORMAÇÃO DE PROFESSORES/AS}

Nesta pesquisa, privilegiaremos o diálogo com autores/as que, de alguma forma, abordam temas que reverberam na produção de conhecimentos contra-hegemônicos, ou mesmo hegemonias alternativas ${ }^{10}$, no campo educacional brasileiro. Esses conhecimentos são traduzidos não apenas em reflexões, mas em formas de atuação capazes de reverter a situação das populações negras no interior de uma sociedade marcada pela lógica perversa de um sistema social estratificado e estruturalmente racializado.

Pensamos, de acordo com Williams (1979), que se qualquer processo hegemônico deve ser especialmente alerta e sensível às alternativas e oposição que lhe questionam ou ameaçam o domínio, justamente desses conhecimentos emergem os esforços e contribuições daqueles/as que estão, de uma forma ou de outra, fora, ou nas margens, dos termos da hegemonia específica.

Esses conhecimentos, que afirmamos enquanto produções intelectuais negras, concordando com Oliveira (2016), expressam-se a partir de uma geração de intelectuais negros/as nas universidades brasileiras que articula a militância política e a produção do conhecimento sobre a realidade étnico-racial fundamentada em sua própria vivência racial, inserindo-se politicamente na luta antirracista e desafiando a universidade e os órgãos do Estado a implementarem políticas afirmativas, notadamente no campo da educação. Na mesma linha de

\footnotetext{
Ver: WILLIAMS, 1979.
} 
raciocínio, Gomes (2010) complementa que ao realizarem pesquisas com a temática étnico-racial, esse grupo de intelectuais negros/as, acima de tudo, assume a questão racial como uma questão social, política demandada na luta antirracista na universidade, com isso, fortalecendo entre si.

A definição de intelectuais negros/as que melhor se adequa a esta pesquisa é elaborada por Macêdo (2013) ao afirmar que,

Ao falar em intelectual negra(o), estou referendando, inicialmente, uma presença física, estética, fenotipicamente diferenciada da maioria não negra que constitui o universo da produção intelectual no Brasil. Uma presença marcada, regulada e (des)conhecida pelo seu lugar de pertencimento racial. Ou seja, estou - de certa forma - reafirmando a identificação mais recorrente na literatura acadêmica acerca desses(as) intelectuais que tomam como referência, para nomeá-los, esse pertencimento. Nessa literatura, o termo, intelectuais negros, ao mesmo tempo em que designa e diferencia, cria certa homogeneidade para um grupo de intelectuais particularizados pelo pertencimento racial e pela experiência de isolamento e discriminação. (MACÊDO, 2013, p. 26)

O intelectual não é apenas alguém que lida com ideias. Intelectual é alguém que lida com ideias transgredindo fronteiras discursivas porque ele ou ela vê a necessidade de fazê-lo. É alguém que lida com ideias em sua vital relação com uma cultura política mais ampla.

Dentre vários aspectos positivos relacionados à inserção destes/as intelectuais negros/as no meio acadêmico, tomando como referência o conceito de Macêdo (2013), destacamos o fato de que eles/elas atuam, enquanto sujeitos coletivos de seu próprio conhecimento científico, ocupando lugares de destaque no cenário acadêmico local e nacional, nas associações de pesquisa e na formação de professores/as. Organizam e criam associações científicas, a exemplo dos Neab's, produzindo conhecimentos com o objetivo de dar visibilidade a subjetividades, desigualdades, silenciamentos e omissões em relação a determinados grupos sociorraciais e suas vivências. Seguimos a ideia de Santos (2008), afirmando que esses sujeitos articulam a militância política e a produção do conhecimento sobre a realidade étnico-racial a partir da sua própria vivência racial.

O diferencial para a formação desses negros intelectuais, no que diz respeito à incorporação e reprodução de um ethos acadêmico ativo, que não admite a colonização intelectual eurocêntrica em seus estudos e pesquisas nem a ausência de propostas de políticas de promoção da igualdade racial - que passou a fazer parte das condutas acadêmica e política desses intelectuais -, não foi somente o ambiente e o conhecimento acadêmico adquirido e elaborado nos cursos de pós-graduação que realizaram em 
universidades públicas e privadas ou mesmo no ofício de intelectuais-acadêmicos. Nos programas de pós-graduação das universidades brasileiras eles adquiriram e incorporaram uma ética acadêmico-científica, que também é condição necessária, mas não suficiente, para a formação destes intelectuais. A incorporação de uma ética da convicção antirracismo, que é a outra condição necessária para a constituição dos negros intelectuais, também foi e é fundamental. Estes podem adquirir ou incorporar tal ética através da influência direta ou indireta dos movimentos sociais negros. (SANTOS, 2008, p. 10)

Cientes do papel da universidade, enquanto lócus privilegiado da produção de conhecimentos, vários Neab's vêm potencializando sua intervenção nos processos de formação inicial e continuada de professores/as, com o intuito de qualificá-los/as em uma perspectiva etnicoracialmente democratizante, como afirma Oliveira (2016).

Consideramos, aqui, a importância que merecem as pesquisas desenvolvidas na área da formação inicial e continuada de professores/as, visto que, segundo os autores Siss, Barreto e Oliveira (2014) há uma parcela significativa de pesquisadores/as dos Neab's que entendem que este campo de discussões é um dos maiores, senão o maior e mais importante desafio colocado para a educação brasileira para uma prática pedagógica eficiente no âmbito de uma sociedade tão diversificada culturalmente como é a nossa. Portanto, discorrermos sobre tal temática implica, necessariamente, levarmos em consideração a complexidade e diversidade de interpretações e respostas que a análise suscita.

Acerca do trato pedagógico para a educação das relações étnico-raciais na formação inicial e continuada de professores/as, concordamos com Baía Coelho e Mauro Cézar Coelho (2015) quando afirmam que o plano de implementação da Lei 10.639/2003 reconhece os Neab's e grupos correlatos instituídos em Instituições de ensino superior como um importante braço de pesquisa e elaboração de material e de formatação de cursos de formação de docentes dentro das temáticas abordadas por este plano. Ainda sobre esse tema, Macêdo e Queiroz (2013) reafirmam que o reconhecimento e ampliação dessas pesquisas, nos diversos espaços acadêmicos, principalmente nos cursos de pós-graduações é um desafio colocado na ordem do dia, caso se pretenda que a Lei 10.639/2003 se torne efetivamente realidade em todas as demais dimensões dos processos educativos.

Sabe-se que a introdução da Lei 10.639/2003 tem gerado alguns impactos na constituição e no fortalecimento dos Neab's. Estes espaços, consequentemente, demandam fortemente e, de dentro das universidades o cumprimento dessa legislação junto às diferentes instâncias acadêmicas intervindo, de forma direta, em vários processos, dentre eles a formação de professores/as nos seus 
aspectos inicial e continuado. Estes processos apontam, diretamente, para a necessidade em discutir e reconhecer a história do povo negro, o papel imprescindível que ela desempenha em ações e projetos antirracistas, de valorização da participação das populações negras na educação e no desencadeamento de uma desejada reconfiguração da nossa memória. Recorremos a Macêdo (2013) para entendermos que

Reconfigurar a memória sobre as populações negras exige descortinar e deslocar do centro a memória racista, edificada a partir de teorias eurocêntricas e/ou de pureza racial, negando-a enquanto memória única e representativa das populações negras e na contramão deste garimpar produção de outras memórias, questionando por que estas outras memórias não fazem parte do panteão reconhecido como a memória nacional. (MACÊDO, 2013, p.242)

Esse deslocamento torna-se necessário, a todo o momento, quando tais teorias eurocêntricas impõem a única forma de conhecimento válido, constituindo-se num dos instrumentos mais eficazes e duradouros da dominação racial pela negação que empreende a legitimidade das formas de conhecimento, produzidos pelas populações negras e, consequentemente, de seus membros enquanto sujeitos de conhecimento. Esse instrumento eficaz de subjugação, de destituição da humanidade, da cultura e civilização do outro é o modus operandi do empreendimento colonial. ${ }^{11}$

Diante de conhecimentos construídos a partir de concepções tão desfavoráveis acerca das populações negras, torna-se imperativo, principalmente na conjuntura brasileira atual, observarmos a importância que produções voltadas para o campo da formação de professores/as e as relações étnico-raciais têm na ampliação da luta antirracista nos processos educacionais, questão basilar desta pesquisa.

\section{DIALOGIA E POLIFONIA: SITUANDO A PRODUÇÃO DA ABPN E DOS NEAB'S A PARTIR DA ANÁLISE TEXTUAL DISCURSIVA}

Buscando compreender o alcance dessas produções na contribuição para a efetivação de uma educação plural e antirracista, esta pesquisa adotará, do ponto de vista do método, a proposta teórica a partir dos estudos de Bakthin, em especial o conceito de dialogia ${ }^{12}$, entrevendo o diálogo produzido por esse grupo de autores e autoras, através de seus textos, partindo do entendimento de que "todo texto tem um autor (que fala e escreve)" (BAKHTIN, 1997, p. 330).

\footnotetext{
${ }^{11} \quad$ Ver: SANTOS (2000, p. 328-329).

12 Ver: BAKHTIN (1997, p. 413).
} 
Estas produções são atravessadas por uma polifonia que os constitui, nos fazendo perceber as múltiplas vozes, desconstruindo a ilusão de unidade que se apresenta nos enunciados. Assim, as potencialidades dos aspectos dialógicos e polifônicos aqui propostos possibilitarão antever, além de pontos de encontro, algumas tensões. Acreditamos que lançando mão destas perspectivas, aventamos.

Um posicionamento político-epistemológico bastante diverso do que o institucionalizado pela ciência moderna, de uma forma geral, e pela educação escolar formal, de uma forma mais específica, possibilitando, consequentemente, um diálogo com saberes fazeres histórica e socialmente invisibilizados. (JÚNIOR; JÚNIOR; PASSOS, 2012, p. 6)

Essa polifonia que as(os) constitui nos faz perceber as múltiplas vozes, permitindo desconstruir a ilusão de unidade que se apresenta nos enunciados. Assim, as potencialidades dos aspectos dialógicos aqui propostos possibilitarão antever, além de pontos de encontro, algumas tensões. (Bakhtin, 2000) "Não basta que haja diversas vozes, antes é preciso que elas se constituam, por meio do diálogo, em pontos de vista contraditórios". (GRILLO, 2005, p. 1165)

Enquanto procedimento metodológico, adotaremos a análise textual discursiva ${ }^{13}$ considerando-a uma abordagem de análise de dados que transita entre duas formas consagradas de análise na pesquisa qualitativa (conteúdo e discurso). Esta abordagem privilegiará as condições que proporcionam a organização e construção de novos entendimentos, observando a multiplicidade de sentidos expressos pelos autores e autoras, através da leitura dos seus textos. Concordamos que

Compreender e ver o autor significa ver e compreender uma outra consciência, isto é, um outro sujeito, aquele que se expressa. $\mathrm{O}$ autor, quando se expressa, faz de si um objeto para o outro e para si mesmo, dando realidade à sua consciência. Assim, compreender implica a presença de duas consciências: a consciência do autor e a consciência de quem toma conhecimento da presença do autor na obra. Esse ato de compreender é dialógico, na medida em que ultrapassa uma lógica previsível, causal ou factual, isto é, a compreensão é sempre diferente para leitores diferentes, em contextos diferentes. (BAKHTIN, 1997, p.12 apud FERNANDES, 2004, p. 182).

Partindo do pressuposto de que todo texto possibilita uma multiplicidade de leituras, tanto em função das intenções dos autores e autoras como em função dos referenciais teóricos dos/as leitores/as e dos campos semânticos em que se inserem, esta pesquisa levará em consideração a exigência da análise textual discursiva na reconstrução dos entendimentos de ciência, superando para-

13 Ver: MORAES; GALIAZZI (2006). 
digmas e solicitando construção de caminhos próprios de pesquisa. (MORAES; GALIAZZI, 2006)

Entendendo que toda análise textual discursiva se concretiza a partir de um conjunto de documentos denominado corpus ${ }^{14}$, os artigos produzidos tanto pela revista da ABPN quanto pelos Neab's (anais dos congressos) passam por uma seleção e delimitação rigorosa. Este processo se inicia com uma unitarização ${ }^{15} \mathrm{em}$ que os textos são separados em unidades de significado, gerando outros conjuntos de unidades oriundas da interlocução empírica, da interlocução teórica e das interpretações feitas pelo pesquisador/a. Neste movimento de interpretação do significado atribuído pelo autor/a, exercitamos a apropriação das palavras de outras vozes para melhor compreensão do texto.

Depois da realização desta unitarização, que precisa ser feita com intensidade e profundidade, passa-se a fazer a articulação de significados semelhantes em um processo denominado de categorização. Neste processo reúnem-se as unidades de significado semelhantes, podendo gerar vários níveis de categorias de análise. A análise textual discursiva tem no exercício da escrita seu fundamento enquanto ferramenta mediadora na produção de significados e por isso, em processos recursivos, a análise se desloca do empírico para a abstração teórica, que só pode ser alcançada se o pesquisador fizer um movimento intenso de interpretação e produção de argumentos. Este processo todo gera meta-textos analíticos que irão compor os textos interpretativos. (MORAES; GALIAZZI, 2006, p. 118)

A utilização da análise textual discursiva tem mostrado tratar-se de uma ferramenta aberta, exigindo dos usuários aprender a conviver com uma abordagem que exige constantemente a (re)construção de caminhos.

\section{CONSIDERAÇÕES FINAIS}

Neste texto, apresentamos algumas reflexões acerca das possíveis contribuições da ABPN e dos Neab's para o campo temático da educação das relações étnico-raciais na formação inicial e continuada de professores/as.

Acreditamos na importância da pesquisa por entender que tanto a ABPN quanto os Neab's têm em comum, além de outras funções, o preparo de professores/as para atender a demanda diversificada de estudos das relações

${ }^{14}$ Ver: MORAES (2003, p. 194).

15 "Unitarizar é interpretar e isolar ideias elementares de sentido sobre os temas investigados. Constitui leitura cuidadosa de vozes de outros sujeitos, processo no qual o pesquisador não pode deixar de assumir suas interpretações. Ao expressar múltiplas vozes, o processo consiste em um diálogo com interlocutores em que participam diversificados pontos de vista, sempre expressos na voz do pesquisador. Na unitarização os textos submetidos à análise são recortados, pulverizados, desconstruídos, sempre a partir das capacidades interpretativas do pesquisador. Nisso fica presente sua autoria, ao mesmo tempo que seu limite". (MORAES; GALIAZZI, 2006, p. 123-124) 
étnico-raciais, no que se refere ao trabalho educativo antirracismo. As formações iniciais e continuadas de professores são elementos fundamentais para isso.

Entendemos que as universidades e os institutos federais de educação, ciência e tecnologia, se constituem como lócus privilegiado de formação de professores, nas suas dimensões inicial e continuada e que precisam fazê-lo na perspectiva da educação das relações etnicoraciais. Essa é uma demanda importantíssima de várias organizações do movimento negro e do segmento afro-brasileiro que se reconhecem como alocados em posição de subalternidade e que desejam romper com essa assimetria relacional.

Pretendemos que as reflexões suscitadas aqui neste texto fortaleçam novas construções/reconstruções que visem à promoção da qualidade de vida de todos os envolvidos e possíveis caminhos institucionais de uma efetiva política de/para a diversidade e na/da inclusão multi, inter e/ou transcultural, favorecendo a construção da justiça social e da cidadania.

Destacamos a importância desta pesquisa para o fortalecimento daqueles/ as espaços que agrupam e estudam o campo da formação de professores/as e as relações raciais, promovendo a ampliação de uma educação mais igualitária e justa.

\section{REFERÊNCIAS}

BAÍA COELHO, Wilma de Nazaré; COELHO, Mauro Cezar. Lugar de formação: a produção intelectual discente sobre ensino de história na pós-graduação stricto sensu na Região Norte. In: História \& Ensino. (jul./dez.). v.21, nº 2. P. 181-207. Londrina, 2015.

BAKHTIN, Mikhail Mikhailovich. Estética da Criação Verbal. São Paulo: Martins Fontes, 2000.

CARDOSO, P. J. F. As ações afirmativas e os desafios da luta pela igualdade na conjuntura atual. Ed. Revista Pedagógica. (jan./abr) v. 19, n. 40. Chapecó, 2017. P. 33-42. Acesso em 2 de Set de 2017. Disponível em: http://dx.doi.org/10.22196/rp.v19i40.3740.

CARDOSO, Paulino. Os núcleos de estudos afro-brasileiros e a associação brasileira de pesquisadores(as) negros(as): desafios. In: ABPN 10 ANOS. I Seminário Virtua: Seminário Estratégico de Fortalecimento Institucional da ABPN. Ed. ABPN. 2013. Acesso em 2 de Set de 2017. Disponível em: https://www.abpn.org.br/revista/index. php/revistaabpni/article/view/192.

FERNANDES, Antônia Terra de Calazans. História e Dialogismo: Uma possibilidade de interpretação histórica e de ensino de história a partir das reflexões de Mikhail Bakhtin. Anais do III Encontro Perspectivas do Ensino de História. Acesso em 2 de Set de 2017. Disponível em: http://ojs.fe.unicamp.br/index.php/FEH/article/view/6025

GOMES, Nilma Lino. Intelectuais negros e produção do conhecimento: algumas reflexões sobre a realidade brasileira. In: SANTOS, Boaventura de Souza; MENEZES, Maria Paula (Orgs.). Epistemologia do Sul. São Paulo Cortez, 2010. P. 492-516. 
JÚNIOR, Luiz Rufino Rodrigues, JÚNIOR, José Carlos Teixeira, PASSOS, Mailsa Carla Pinto. Ambientes Polifônicos: Notas sobre as práticas musicais afrodiaspóricas e o cotidiano escolar. XVI ENDIPE - Encontro Nacional de Didática e Práticas de Ensino - UNICAMP - Campinas - 2012. Acesso em 2 de Set de 2017. Disponível em: http://www.infoteca.inf.br/endipe//acervo/listar/todos/8

MACEDO, Marluce de Lima, QUEIROZ, Delcele Mascarenhas. A produção de estudos sobre a lei 10.639 nas regiões norte e nordeste. In: Revista Educação e Políticas em Debate. v. 2, n. 1 - (jan./jul). 2013. Acesso em 2 de Set de 2017. Disponível em: http://www.seer.ufu.br/index.php/revistaeducaopoliticas.

MACEDO, Marluce de Lima. Intelectuais Negros, Memória e Diálogos para uma Educação Antirracista: uma leitura de Abdias do Nascimento e Edison Carneiro. Tese (Doutorado). Salvador, 2013.

MARQUES, Eugenia Portela de Siqueira, MATTOS, Wilson Roberto de. Educação, relações étnico-raciais e resistência: as experiências dos Núcleos de Estudos Afrobrasileiros e Indígenas no Brasil. Ed. Assis: Triunfal Gráfica e Editora. Salvador, 2016. P. 05.

MORAES, Roque, GALIAZZI, Maria do Carmo. Análise textual discursiva: processo reconstrutivo de múltiplas faces. Ciência \& Educação (Bauru), vol. 12, núm. 1, abril, 2006, pp. 117-128 Universidade Estadual Paulista Júlio de Mesquita Filho, São Paulo. Acesso em 4 de Jul de 2017. Disponível em: http://www.scielo.br/scielo.php?pid=S1516$73132006000100009 \&$ script=sci_abstract\&tlng=pt

OLIVEIRA, Iolanda de. Negros e educação no Brasil: uma entrevista com o coração de uma militante acadêmica. PERSPECTIVA, Florianópolis, v. 28, $\mathrm{n}^{\circ}$ 1, P. 213 - 224, jan./jun. 2010.

OLIVEIRA, Otair Fernandes de. Intelectualidade Negra e produção do conhecimento na Educação Brasileira. In: Revista ensaios e pesquisa em Educação. Vol. o1. Segundo semestre. 2016. P. $106-118$.

O conceito de hegemonia na luta contra o racismo no brasil: a função dos NEAB's. In: Cadernos do Centro de Ciências Sociais da Universidade do Estado do Rio de Janeiro. vol.7. $\mathrm{n}^{\circ}$ 2. Rio de Janeiro, 2014. P. 191-204.

SANTOS, Boaventura de Sousa. Pela Mão de Alice: o social e o político na pósmodernidade. Ed. Cortez. $7^{\mathrm{a}}$. ed. São Paulo, 2000.

SANTOS, Sales Augusto dos. De militantes negros a negros intelectuais. V Congresso Português de Sociologia (Anais). Universidade Nova de Lisboa. Lisboa, 2008.

SISS, Ahyas, BARRETO Maria Aparecida Santos Corrêa, OLIVEIRA, Otair Fernandes de. Processos formativos e as contribuições dos Núcleos de Estudos Afro-Brasileiros da UFES e da UFRRJ. Ed. UFRRJ. Rio de Janeiro, 2013. Acesso em 2 de Set de 2017. Disponível em: http://www.e-publicacoes.uerj.br/index.php/revistateias/article/ view/24344. 
Ações Afirmativas, Educação Superior e NEABS: interseções históricas. In: Cadernos do Centro de Ciências Sociais da Universidade do Estado do Rio de Janeiro. vol.7, $\mathrm{n}^{\circ} 2$. Rio de Janeiro, 2014. P. $181-190$.

WILLIAMS, Raymond. Marxismo e literatura. Rio de Janeiro: Zahar, 1979. 